\title{
Does Emission Trading Improve Carbon Emission Efficiency of China's Iron and Steel Industry? An Exploration Using a DEA-SBM and Difference-In- Differences Approach
}

\author{
Xiping Wang \\ North China Electric Power University - Baoding Campus \\ Sujing Wang ( $\sim 975843674 @ q q . c o m$ ) \\ North China Electric Power University - Baoding Campus
}

\section{Research Article}

Keywords: Emission trading, Carbon emission efficiency, China's iron and steel industry, DEA-SBM, Difference-in-differences

Posted Date: July 13th, 2021

DOl: https://doi.org/10.21203/rs.3.rs-626027/v1

License: (c) (1) This work is licensed under a Creative Commons Attribution 4.0 International License. Read Full License 
1 Does emission trading improve carbon emission

2

\title{
efficiency of China's iron and steel industry? An
}

\section{exploration using a DEA-SBM and}

\section{difference-in-differences approach}

\author{
Xiping Wang $1^{1}$, Sujing Wang ${ }^{2}$ \\ ${ }^{*}$ Corresponding author. E-mail address: 975843674@qq.com; Tel.: +86-159-1105-1132.
}

Abstract: As an effective tool of carbon emission reduction, emission trading has been widely used in many countries. Since 2013, China implemented carbon emission trading in seven provinces and cities, with iron and steel industry included in the first batch of pilot industries. This study attempts to explore the policy effect of emission trading on iron and steel industry in order to provide data and theoretical support for the low-carbon development of iron and steel industry as well as the optimization of carbon market. With panel data of China's 29 provinces from 2006 to 2017, this study adopted a DEA-SBM model to measure carbon emission efficiency of China's iron and steel industry (CEI) and a difference-in-differences (DID) method to explore the impact of emission trading on CEI. Moreover, regional heterogeneity and influencing mechanisms were further investigated, respectively. The results indicate that: (1) China's emission trading has a significant and sustained effect on carbon abatement of iron and steel industry, increasing the annual average CEI by $12.6 \%$ in pilot provinces. (2) The policy effects are heterogeneous across diverse regions. Higher impacts are found in the western and eastern regions, whereas the central region is not significant. (3) Emission trading improves CEI by stimulating technology innovation, reducing energy intensity, and adjusting energy structure. (4) Economic level and industrial structure are negatively related to CEI, while environmental governance and openness degree have no obvious impacts. Finally, according to the results and conclusions, some specific suggestions are proposed.

Keywords: Emission trading; Carbon emission efficiency; China's iron and steel industry; DEA-SBM; Difference-in-differences

\section{Introduction}

The climate warming caused by emissions of greenhouse gases, especially $\mathrm{CO}_{2}$, has aroused

\footnotetext{
${ }^{1}$ Department of Economics and Management, North China Electric Power University, Baoding, China; E-Mails: 954419367@gq.com;

${ }^{2}$ Department of Economics and Management, North China Electric Power University, Baoding, China; E-Mails: 
widespread concerns around the globe. Since the signing of Paris Agreement, countries have formulated their own emission reduction schemes. As a responsible country, China has always actively participated in carbon emission reduction and put forward a series of policies and measures, such as "40-45\% reduction in $\mathrm{CO}_{2}$ emissions per unit gross domestic product (GDP) in 2020 compared with 2005 " and "60-65\% reduction in $\mathrm{CO}_{2}$ emissions per unit GDP around 2030 compared with 2005." (Zhou et al., 2019). In order to enhance national contributions, China took more powerful measures and set the "30 60" goal in September 2020, that is, to achieve carbon peak in 2030 and achieve carbon neutrality in 2060. Faced with these propositions of the times, iron and steel industry, as a high carbon emission industry, bears great responsibilities. China is the world's largest producer and consumer of crude iron and steel, accounting for $57 \%$ of global crude iron and steel production in 2020, which results in a large number of carbon emissions. Specifically, the carbon emissions of China's iron and steel industry account for about $15 \%$ of total carbon emissions of the country and more than $60 \%$ of the global carbon emission of iron and steel industry. Therefore, to reach energy conservation and emission reduction objectives, it is urgent for iron and steel industry to explore low-carbon development path.

Emission trading is generally recognized as an effective tool to reduce carbon emissions and alleviate climate warming. Since the United Nations issued "United Nations Framework Convention on Climate Change" and "Kyoto Protocol", emission trading has been carried out in many countries. At present, there are 21 emission trading systems under operation, covering about $10 \%$ of global carbon emissions. In October 2011, China issued "Notice on Pilot Work of Carbon Emission Trading”, and established emission trading pilot programs in seven provinces and cities since 2013. Meanwhile, power, iron and steel, non-ferrous and other industries were included in the first batch of pilot industries. By the end of 2020, national carbon market quota spot had accumulated 445 million tons, with a turnover of 10.331 billion Yuan. In general, China's emission trading has achieved remarkable results, but the policy effect of diverse industries may be different. Accordingly, it is necessary to analyze specific industries separately.

As iron and steel industry is one of the pilot industries, whether emission trading is applicable and how effective it is remain to be further evaluated. Due to the relatively low carbon emission efficiency, improving the efficiency is essential for reducing carbon emissions of iron and steel industry. For this reason, by combining a policy evaluation method (DID) with an efficiency measurement model (DEA-SBM), this study explored the effect of emission trading on carbon emission efficiency of China's iron and steel industry (CEI), which contributes to the low-carbon development of iron and steel industry as well as the optimization of carbon market.

The rest of this paper is arranged as follows. Section 2 briefly reviews the existing literature and illustrates our main contributions. Section 3 puts forward theoretical analysis and research hypothesis. Methodology and data are introduced in section 4. Section 5 presents and discusses the empirical results. Section 6 summarizes the main conclusions and points out the corresponding policy implications.

\section{Literature review}


With the increasingly higher pressure of carbon emission reduction, the evaluation of emission trading has been a popular research topic. Although domestic and international carbon markets are not synchronous, the research results are similar. Numerous studies estimate the policy effects of emission trading by applying computable general equilibrium (CGE) model and difference-in-differences (DID) method. CGE model is the most widely used, but it is difficult to track its influencing mechanisms due to its complex internal design, while DID method is very popular in recent years, which can more accurately reflect the real policy effect. As for the research conclusion, it mainly focuses on the economic and environmental effects of emission trading.

In terms of economic effects, scholars have carried out a series of studies but no unified conclusion has been reached. Some studies support positive effects, but others find negative impacts. Dong et al. (2019) figured out that in the long run, emission trading scheme (ETS) can stimulate sustainable economic and environmental dividends. Fare and Ahmed (2014) argued that ETS can bring great economic dividends to enterprises. Likewise, Springer et al. (2019) demonstrated that China's ETS can enable regulated enterprises to reduce emissions at a lower cost under current structural changes in the economy. Hübler et al. (2014) and Wang et al. (2009) studied the GDP loss caused by China's ETS, and the former found that the GDP loss can be controlled at about $1 \%$, while the latter predicted that the GDP loss is $0.28 \%$. Tran et al. (2019) suggest that the implementation of ETS reduce Australia's GDP and household consumption to a large extent. Similarly, Nong et al. (2020) discovered that ETS reduced Vietnam's GDP by $4.57 \%$.

With respect to environmental effects, most scholars generally hold that emission trading plays a vital role in carbon emission reduction. They mainly investigate the emission reduction effect based on total carbon emissions and carbon intensity form the national level. Wang et al. (2019) utilized provincial data and DID method to find that China's ETS can significantly reduce carbon intensity and promote China's low-carbon transition. Based on the panel data from 2007 to 2016, Chen et al. (2020a) also adopted a DID method to explore the carbon abatement effect of China's pilot ETSs, and found that the total carbon emission of pilot regions decreased by $13.39 \%$, while $\mathrm{Hu}$ et al. (2020) found that the carbon emissions decreased by $15.5 \%$. Zhang et al. (2019a) estimated the net dynamic impact of China's ETS on low-carbon development in terms of $\mathrm{CO}_{2}$ emissions, carbon intensity, energy consumption and energy intensity, and the results showed that the impact of ETS policy on low-carbon development would gradually increase over time. Similar studies include Wen et al. (2020), Zhang et al. (2019b) and Shen et al. (2020) which find basically consistent conclusions. Overall, those studies generally confirm the positive effect of emission trading on carbon reduction.

Another research direction is to investigate influencing channels of emission trading. Zhou et al. (2020) hold that ETS mainly reduces the carbon emission intensity of pilot provinces by adjusting industrial structure, while energy structure and energy intensity channels have not been realized yet. Tang et al. (2020) conducted a mediating effect analysis and conclude that the ETS reduces the carbon intensity via increasing the proportion of tertiary industry output value in GDP and decreasing the energy intensity. Some other studies focus on the influencing channels of emission trading from the perspective of technological progress and energy intensity (Zhang et al., 2017; Yang et al., 2016). 
In addition to the national level, some studies have concentrated on specific industries. Using DID method, Zhang et al. (2019c) discovered that the ETS reduced industrial carbon emissions by $10.1 \%$ and carbon intensity by $0.78 \%$. However, there are significant differences in emission reduction effects of emission trading scheme on various industrial sectors (Cheng et al., 2015; Cheng et al., 2008). Much attention is paid to the application of emission trading in the fields of power, manufacturing and aviation (Anger, 2009; Chen et al., 2008; Shen et al., 2016; Alberola et al., 2008; Zhang et al., 2018). Due to a relative shortage of free quotas in the cement, mineral, electricity and iron and steel industries, participation in the trading market may increase production costs of these enterprises (Li et al., 2016; Deng et al., 2018).

The cement and power industries with relatively low cost of emission reduction, can maximize profits by selling large amounts of quotas. In contrast, iron and steel industry with high carbon emission reduction costs must purchase a large number of quotas (Wang et al., 2015; Xian et al., 2019). Taking EU ETS as an example, Kara et al.(2008) suggested that the power industry will gain huge profits from the carbon trading market, but iron and steel industry will be the biggest losers due to the resulting rise in electricity prices. For energy-intensive manufacturing, different sub-sectors will be affected by the EU ETS in different ways, with the cost impact of iron and steel and cement industries being 3-4 times greater than that of the paper and oil refining industries (Lund, 2007). Several studies have been conducted specifically on the impact of emission trading on iron and steel industry. Tao (2017) established a two-layer programming model with random factors to study the optimal production of iron and steel under the carbon emission trading mechanism. Hidalgo et al. (2004) proposed a recursive world simulation model, ISIM model, to analyze the potential impact of carbon trading on iron and steel industry. Demailly et al. (2007) quantified the impact of the European Emissions Trading Scheme on the competitiveness, output and profitability of iron and steel industry. Duan et al. (2019) built a two-stage dynamic game model and found that emission trading scheme is conducive to the improvement of the economic level and emission reduction level of iron and steel industry.

To sum up, The above studies demonstrate that the DID model is a mature method suitable for assessing the impact of emission trading and the results can be clearly explained. In addition, most research results indicate that emissions trading plays a significant role in carbon emission reduction. However, relevant literature is mainly based on the whole country and lacks in-depth analysis of specific industrial sectors, which may hinder the effective implementation of emission trading. In addition, the effects of emission trading on total carbon emissions and carbon emission intensity are widely studied, while few studies concentrate on carbon emission efficiency. Moreover, further investigation of influencing channels is limited.

This paper expands and innovates on the basis of previous research, and the main contributions are as follows: (1) A DID method is used to evaluate the effect of emission trading on iron and steel industry, which enriches the empirical evidence of emission trading from the industry level. (2) A DEA-SBM model is employed to measure carbon emission efficiency of China's iron and steel industry, which considers multiple input and output indexes and thus obtains more accurate results. (3) Considering the characteristics of iron and steel industry, technology innovation, energy intensity and 
energy structure are treated as mediating variables to further explore the influencing mechanisms of emission trading. Overall, this study not only contributes to the green development of iron and steel industry but also provides vital guidelines for the effective implementation of emission trading in China and other countries.

\section{Theoretical analysis and research hypothesis}

The essence of emission trading is emission right, which is endowed with the attribute of "commodity" in carbon market. To be specific, the government sets a total carbon emission goal and issues emission quotas to enterprises according to actual situation. On the one hand, enterprises with high carbon emissions can reduce emission costs by purchasing quotas; on the other hand, enterprises with low carbon emissions can obtain additional profits by selling quotas. This virtuous cycle can effectively achieve the goal of energy conservation and emission reduction. Accordingly, this paper holds that emission trading helps to improve carbon emission efficiency of China's iron and steel industry (CEI), and thereby achieve the carbon emission reduction target. Thus, we propose the first hypothesis:

H1: Emission trading is conductive to improving carbon emission efficiency of China's iron and steel industry (CEI).

According to the characters of iron and steel industry, we further investigate the influencing channels from three aspects: technology innovation, energy intensity and energy structure.

Firstly, technology innovation is the key to achieve carbon emission reduction in iron and steel industry, but at present, the low-carbon technology is relatively backward and there is a lot of room for improvement. In the case of emission trading, enterprises would carefully weigh the cost of purchasing quotas and developing technology. Meanwhile, uncertainty about the carbon price increases risks faced by enterprises. In addition, extra profits from the sale of the quotas is also an incentive to promote low-carbon technology innovation. Therefore, enterprises tend to increase their R\&D investment to reduce emission costs and carbon risks. Based on the above analysis, this paper puts forward the following hypotheses:

H2: Emission trading is conductive to improving CEI by stimulating technology innovation.

Secondly, high energy intensity is an important reason for low carbon emission efficiency of iron and steel industry. In recent years, China's energy intensity (energy consumption per unit of GDP) has declined to a certain extent, but there is still a large gap compared with the world average level. For a long time, due to the needs of economic development, energy prices are relatively undervalued, resulting in excessive use of energy. Under the emission trading, enterprises faced with high carbon emission costs, would try to reduce energy consumption intensity and improve energy utilization efficiency. Consequently, this paper hypothesizes that:

H3: Emission trading is conductive to improving CEI by reducing energy intensity.

Thirdly, as an energy and emission intensive industry, the energy structure of iron and steel 
industry is extremely unreasonable. High proportion of traditional fossil energy such as coal and oil leads to low carbon emission efficiency, which exerts great pressure on emission reduction. Through market-oriented adjustment, emission trading promotes the rationalization of price negotiation from the aspects of property rights, emission reduction costs and the supply and demand relationship of carbon emission permits. In view of long-term economic benefits, companies would reconsider the allocation of energy inputs, and then adjust energy structure, using clean energy to replace traditional fossil energy. Thus, this paper hypothesizes that:

H4: Emission trading is conductive to improving CEI by adjusting energy structure.

\section{Methodology and data}

\subsection{DEA-SBM model}

Data envelopment analysis (DEA) is a commonly used method for efficiency measurement, which evaluates the relative effectiveness of multiple input-output indexes in homogeneous decision making units (DMUs) by linear programming. However, traditional DEA ignores the slack of input and output variables and thus the efficiency value obtained may be biased. For this reason, Tone (2001) proposes a non-radial, non-angled DEA, slack based measurement (SBM), which effectively solves the slack problem and thereby enables more accurate efficiency evaluation. Consequently, this paper employed a DEA-SBM model to measure the carbon emission efficiency of iron and steel industry. The model function is expressed as follows.

$$
\begin{aligned}
& \min \rho=\frac{1-\frac{1}{m} \sum_{i=1}^{m} s_{i}^{-} / x_{i k}}{1+\frac{1}{q_{1}+q_{2}}\left(\sum_{r=1}^{q_{1}} s_{r}^{+} / y_{r k}+\sum_{t=1}^{q_{2}} s_{t}^{b-} / b_{r k}\right)} \\
& \text { s.t. } X \lambda+s^{-}=x_{k} \\
& Y \lambda-s^{+}=y_{k} \\
& B \lambda+s^{b-}=b_{k} \\
& \lambda, s^{-}, s^{+} \geq 0
\end{aligned}
$$

where $\rho$ is the carbon emission efficiency of China's iron and steel industry (CEI). $m, q_{1}$, and $q_{2}$ respectively represent the number of input, desirable output, and undesirable output. $X, Y$, and $B$ respectively indicate the vector of input, desirable output and undesirable output. $s_{i}^{-}$is input redundancy, $s_{t}^{b-}$ is undesirable output redundancy, and $s_{r}^{+}$is desirable output insufficient. $x_{i k}, y_{r k}, b_{r k}$ respectively stand for input, desirable output, and undesirable output of the DMU in a certain period. $\lambda$ is the weight vector of different DMUs. The objective function value $\rho$ decreases monotonically with respect to $s_{i}^{-} 、 s_{r}^{+} 、 s_{t}^{b-}$, and $0<\rho \leq 1$. When $\rho=1$, the evaluated DMU is perfect effective, while $\rho<1$ 
implies that the DMU is not effective and there is potential for improving CEI.

\subsection{Difference-in-differences (DID) method}

The impact of emission trading on CEI can be estimated by a DID method, which is a widely used method for policy evaluation. The DID method divides the samples into treatment group and control group, in which the treatment group refers to the objects affected by the policy, while the control group refers to the objects not affected by the policy. Then the policy effect is estimated by comparing the changes of two groups before and after the policy implementation, which can reduce endogeneity problems to a large extent and thereby obtain a relatively accurate evaluation.

In 2013, China started carbon emission trading pilot programs in seven provinces and cities including Beijing, Tianjin, Shanghai, Chongqing, Hubei, Guangdong and Shenzhen. To ensure the consistent research scope, Shenzhen is merged into Guangdong, since all the other provinces are provincial administrative regions. As a result, we use these 6 pilot provinces as the treatment group, and the remaining non-pilot provinces as the control group. Considering that the actual transaction of emission trading was started between late 2013 and early 2014, this paper takes 2014 as the policy impact year, that is, the non-pilot period before 2014 and the pilot period after 2014. Moreover, control variables are added into the model for avoiding missing variables. The DID method is expressed as follows:

$$
C E I_{i t}=\beta_{0}+\beta_{1} \times \text { Treat }_{i} \times Y_{t}+\sum \gamma_{j} \text { Control }_{j i t}+\varepsilon_{i t}
$$

where $C E I_{i t}$ indicates the carbon emission efficiency of iron and steel industry of province $i$ in year $t$, Treat $t_{i}$ is a sorting dummy that judges whether the province belongs to the treatment group, and equals 1 if province $\mathrm{i}$ is a pilot area, otherwise equals $0 . Y_{t}$ is a time dummy that equals 0 before the policy implementation and equals 1 after that. Control $l_{j i t}$ is a set of control variables, and $\varepsilon_{i t}$ is the error term. Accordingly, if the coefficient $\beta_{l}$ on the interactive term $\left(\right.$ Treat $\left._{i} \times Y_{t}\right)$ is significant at a certain statistical level, emission trading has a significant impact on CEI.

Using DID method needs to meet the parallel trend hypothesis, that is, the change trends for the treatment and control group are the same before the implementation, otherwise the estimated results will be biased. For this reason, Model (3) is built on the basis of Model (2) for parallel trend hypothesis test:

$$
C E I_{i t}=\beta_{0}+\sum_{t=2014}^{2017} \beta_{t} \times \text { Treat }_{i} \times Y_{t}+\sum \gamma_{j} \text { Control }_{j i t}+\varepsilon_{i t}
$$

where Treat $_{i} \times Y_{t}$ is the dummy variable indicating the year to which the pilot region belongs: when the year is $t$ and the province is among the pilot regions, it takes a value of 1 ; otherwise it is 0 . If the coefficient $\beta_{2006}-\beta_{2013}$ is not significant, the model satisfy the parallel trend hypothesis. Additionally, we further examine the dynamic effect and establish the model (4): 


$$
C E I_{i t}=\beta_{0}+\sum_{t=2014}^{2017} \beta_{t} \times \text { Treat }_{i} \times Y_{t}+\sum \gamma_{j} \text { Control }_{j i t}+\varepsilon_{i t}
$$

Where the coefficient $\beta_{2014}-\beta_{2017}$ reflects the dynamic effect of emission trading, that is, whether the policy has a sustained and significant impact on the carbon emission efficiency of iron and steel industry over time.

\subsection{Mediating model}

To further explore the influence paths of emission trading, we constructed the following mediating model to investigate whether emission trading improves CEI by stimulating technology innovation, reducing energy intensity, and adjusting energy structure. The mediating effect model is as follows:

$$
C E I_{i t}=\beta_{0}+\beta_{1} \times \text { Treat }_{i} \times Y_{t}+\sum \gamma_{j} \text { Control }_{j i t}+\varepsilon_{i t}
$$

$$
M_{i t}=\beta_{0}+\beta_{2} \times \text { Treat }_{i} \times Y_{t}+\sum \gamma_{j} \text { Control }_{j i t}+\varepsilon_{i t}
$$

$$
C E I_{i t}=\beta_{0}+\beta_{3} \times \text { Treat }_{i} \times Y_{t}+\beta_{4} M_{i t}+\sum \gamma_{j} \text { Control }_{j i t}+\varepsilon_{i t}
$$

where $M_{i t}$ represents the mediating variables. Firstly, we performed a regression on model (5) to test whether the coefficient $\beta_{1}$ is significant. If so, emission trading has an obvious impact on CEI and we move on to the next step, otherwise we stop the mediating effect test. Secondly, Eq. (6) is used to investigate whether emission trading affects the $M$. If the coefficient $\beta_{2}$ is significant, emission trading has a significant effect on the mediating variable. Finally, based on Eq. (7), the effect of emission trading and $\mathrm{M}$ on ECI are examined simultaneously. If $\beta_{4}$ is significant and the absolute value of $\beta_{3}$ is lower than $\beta_{1}$, the mediating effect exists.

\subsection{Variables and data}

\subsubsection{Dependent variable}

CEI is the dependent variable that denotes the carbon emission efficiency of iron and steel industry of each province. Treating energy, capital and labor as input indexes, total output value as the desirable output and $\mathrm{CO}_{2}$ emissions as the undesirable output, this paper employs a DEA-SBM model to calculate the carbon emission efficiency of iron and steel industry (CEI). Energy input is expressed by energy consumption of iron and steel industry and converted into standard coal. Capital investment is represented by fixed asset investment of iron and steel industry. Labor input is measured by the number of employees at the end of the year. To be clear, the iron and steel industry's relevant energy consumption and economic data were derived from the ferrous metal smelting and calendering processing industry in the statistical yearbook. Moreover, the calculation of $\mathrm{CO}_{2}$ emissions refers to IPCC (2006) and Duan et al. (2016). 


\subsubsection{Independent variable}

As we described previously, the dummy variable Treat $\times Y$ representing emission trading is treated as the independent variable. Treat $\times Y$ is 1 only when the province is among the pilot regions and the year is greater than or equal to 2014; otherwise, it is 0 . The coefficient of Treat $\times Y$ reflects the impact of emission trading on carbon emission efficiency of China's iron and steel industry.

\subsubsection{Control variables}

Referring to existing research and considering the availability of data, the control variables selected in this paper are as follows: average wage of urban employees for measuring the economic development level (lnwage); the ratio of secondary industry output value to represent the industry structure (lnind); the number of R\&D people to symbolize the technical level $(\ln r d)$; the electricity consumption per GDP to denote the energy intensity (lnene); the proportion of total environmental governance investment in GDP to express the environmental regulation (lnenr); the ratio of total import and export to GDP to evaluate the openness level (lnopen).

\subsubsection{Mediating variables}

The mediating variables in this article include technical level (same as above), energy intensity(same as above) and energy structure, which is measured by the proportion of clean energy consumption (the proportion of clean energy consumption represented by natural gas and electricity in the total energy consumption), expressed as lnest.

\subsection{Data collection}

Research data covers China's 29 provinces between 2006 and 2017 (due to the lack of data, Hainan, Tibet, Hong Kong, Macao and Taiwan are not included). The required data are collected from China iron and steel Industry Statistical Yearbook, China Statistical Yearbook, China Energy Statistical Yearbook and China Electric Power Yearbook. To be clear, all price data has been adjusted based on 2004 price index to eliminate the influence of price fluctuations, and all variables are logarithmically processed to eliminate the effect of heteroscedasticity. In addition, Maxdea software is used to calculate the efficiency (CEI), and Stata software is used for econometric analysis.

\subsection{Descriptive statistics}

Table 1 reports the descriptive statistical results of the variables. Obviously, the average CEI of the treatment group is 0.589 , which is significantly higher than that of the control group (0.317), indicating that China's emission trading may improve the carbon emission efficiency of iron and steel industry to a certain extent. Of course, it needs to be verified by empirical analysis and draw further conclusions.

Table 1 Descriptive statistics of variables 


\begin{tabular}{|c|c|c|c|c|c|c|c|}
\hline \multirow[t]{2}{*}{ Variables } & \multirow[t]{2}{*}{ Description } & \multicolumn{2}{|c|}{ All samples } & \multicolumn{2}{|c|}{ Treatment group } & \multicolumn{2}{|c|}{ Control group } \\
\hline & & Mean & Std. Dev. & Mean & Std. Dev. & Mean & Std. Dev. \\
\hline CEI & - & 0.374 & 0.268 & 0.589 & 0.336 & 0.317 & 0.215 \\
\hline Treat $\times Y$ & - & 0.069 & 0.254 & 0.333 & 0.475 & 0.000 & 0.000 \\
\hline lnwage & Yuan/person, log value & 10.600 & 0.449 & 10.871 & 0.489 & 10.530 & 0.410 \\
\hline $\ln r d$ & Person, log value & 10.992 & 1.102 & 11.737 & 0.760 & 10.798 & 1.095 \\
\hline lnind & $\%, \log$ value & 3.779 & 0.198 & 3.655 & 0.318 & 3.811 & 0.136 \\
\hline lnene & kWh/yuan, log value & -2.050 & 0.708 & -2.791 & 0.596 & -1.857 & 0.599 \\
\hline lnenr & $\%, \log$ value & 0.273 & 0.495 & 0.074 & 0.528 & 0.325 & 0.474 \\
\hline lnopen & $\%, \log$ value & -1.700 & 0.994 & -0.631 & 1.046 & -1.979 & 0.765 \\
\hline lnest & $\%$, log value & 2.544 & 0.849 & 2.846 & 0.417 & 1.465 & 0.913 \\
\hline
\end{tabular}

\section{Empirical results and discussion}

\subsection{Analysis of DID regression results}

Based on model (2), this study investigates the impact of emission trading on carbon emission efficiency of China's iron and steel industry. To ensure the robustness of the estimation coefficient, DID regression is performed respectively with and without control variables, fixed province and time-province double fixed. As can be seen intuitively from the Table 2, there is no fundamental change in the direction and significance of the coefficient Treat $X Y$ in various conditions. In conclusion, emission trading significantly improves the carbon emission efficiency of iron and steel industry in the pilot areas and thereby promotes the carbon emission reduction, so $\mathrm{H} 1$ is verified. According to column (4), the implementation of emission trading increases the annual CEI of pilot areas by $12.6 \%$ on average. At present, China's iron and steel enterprises that have participated in the carbon market account for 1/7 of the country's crude steel output. By carrying out MRV (the process of carbon emission quantification and data quality assurance), carbon verification training and other basic capacity building, the enterprises have achieved initial results in energy saving and carbon reduction.

In terms of control variables, economic development, industrial structure, and energy intensity are significantly negatively correlated with CEI, while technical level shows a positive effect. In addition, environmental regulation and openness degree show no significant impacts. First of all, in the process of economic development, a lot of iron and steel resources need to be invested, leading to a substantial increase in carbon emissions, which aggravates environmental pollution to a certain extent. Moreover, the secondary industry still occupies a large proportion in China's industrial structure, and the secondary industry is mostly heavy industry with high energy consumption. The more output value 

created, the more carbon emissions will be emitted, which results in the reduction of carbon emission

325 efficiency. As a high carbon emission industry, iron and steel industry mainly relies on technology

326 innovation to achieve carbon abatement and thereby improve emission efficiency.

327 Table 2 The results of DID regression

\begin{tabular}{|c|c|c|c|c|}
\hline Variables & (1) & (2) & (3) & (4) \\
\hline \multirow[t]{2}{*}{ Treat $\times Y$} & $0.159^{* * *}$ & $0.105^{* *}$ & $0.113^{* * *}$ & $0.126^{* * *}$ \\
\hline & $(4.28)$ & $(2.38)$ & $(2.95)$ & $(3.29)$ \\
\hline \multirow[t]{2}{*}{ lnwage } & & $0.0834^{* * *}$ & $-0.0931^{* *}$ & $-0.408^{* *}$ \\
\hline & & $(2.84)$ & $(-2.01)$ & $(-2.14)$ \\
\hline \multirow[t]{2}{*}{$\operatorname{lnrd}$} & & $0.0970^{* * *}$ & $0.179^{* * *}$ & $0.0948^{*}$ \\
\hline & & $(6.06)$ & $(3.55)$ & $(1.79)$ \\
\hline \multirow[t]{2}{*}{ lnind } & & $-0.202^{* * *}$ & -0.181 & $-0.277^{* *}$ \\
\hline & & $(-3.15)$ & $(-1.51)$ & $(-2.03)$ \\
\hline \multirow[t]{2}{*}{ lnene } & & $0.0825^{* * *}$ & $-0.136^{* *}$ & $-0.135^{* *}$ \\
\hline & & $(3.23)$ & $(-2.34)$ & $(-2.36)$ \\
\hline \multirow[t]{2}{*}{ lnenr } & & 0.0199 & $0.0591^{* *}$ & 0.0300 \\
\hline & & $(0.89)$ & $(2.18)$ & $(1.10)$ \\
\hline \multirow[t]{2}{*}{ lnopen } & & $0.131^{* * *}$ & 0.0216 & 0.0244 \\
\hline & & $(9.86)$ & $(0.66)$ & $(0.70)$ \\
\hline Province fixed & yes & no & yes & yes \\
\hline Year fixed & yes & no & no & yes \\
\hline \multirow[t]{2}{*}{ _cons } & $0.801^{* * *}$ & -0.434 & -0.302 & $4.313^{* *}$ \\
\hline & (17.43) & $(-1.04)$ & $(-0.57)$ & $(2.05)$ \\
\hline $\mathrm{N}$ & 348 & 348 & 348 & 348 \\
\hline$A-R^{2}$ & 0.756 & 0.561 & 0.750 & 0.768 \\
\hline
\end{tabular}
the $1 \%, 5 \%$, and $10 \%$ levels, respectively.(The same below) 
The test results of parallel trend and dynamic effect are shown in Table 3. The coefficients of Treat $\times Y$ are significantly negative from 2006 to 2009, which may be related to high energy consumption and the high pollution caused by rapid economic development during this period. The coefficients of Treat $\times Y$ from 2010 to 2013 are not significant and fluctuates around the value of 0 , which indicates that, on the whole, the parallel trend hypothesis is satisfied. Consequently, it is reasonable to use DID method for evaluation.

According to the dynamic effect regression results, the coefficients of Treat $\times Y$ are significantly positive between 2014 and 2017, which further confirms the conclusion that emission trading has a significant and sustained effect on CEI. Meanwhile, the absolute value increased from 12.7\% in 2014 to $16.2 \%$ in 2017 , indicating that the effect has enhanced obviously. Noteworthily, the carbon emission reduction effect of the policy declined in the second year of implementation. Due to the short year of emission trading pilot, the corresponding market rules and supporting policies are not perfect, and there are still some defects, such as asymmetric information, inconsistent verification, no flow of trading, and lax punishment for violations, which hinder the healthy development of carbon trading market and reduce the enthusiasm of enterprises. Subsequently, the government took a series of measures to solve these problems. In 2016, the policy effect rebounded and reached the maximum value in 2017. In general, the carbon emission reduction of emission trading in iron and steel industry is gradually enhanced with the passage of time.

Table 3 Parallel trend and dynamic effect

\begin{tabular}{|c|c|c|c|c|}
\hline \multirow[t]{2}{*}{ Variables } & \multicolumn{2}{|c|}{ Parallel trend } & \multicolumn{2}{|c|}{ Dynamic effect } \\
\hline & (1) & (2) & (3) & (4) \\
\hline \multirow[t]{2}{*}{ Treat $\times Y_{2006}$} & $-0.355^{* * *}$ & $-0.323^{* * *}$ & & \\
\hline & $(-5.81)$ & $(-5.04)$ & & \\
\hline \multirow[t]{2}{*}{ Treat $\times Y_{2007}$} & $-0.425^{* * *}$ & $-0.400^{* * *}$ & & \\
\hline & $(-6.95)$ & $(-6.40)$ & & \\
\hline \multirow[t]{2}{*}{ Treat $\times Y_{2008}$} & $-0.270^{* * *}$ & $-0.245^{* * *}$ & & \\
\hline & $(-4.42)$ & $(-3.95)$ & & \\
\hline \multirow[t]{2}{*}{ Treat $\times Y_{2009}$} & $-0.236^{* * *}$ & $-0.225^{* * *}$ & & \\
\hline & $(-3.87)$ & $(-3.63)$ & & \\
\hline \multirow[t]{2}{*}{ Treat $\times Y_{2010}$} & -0.00541 & 0.00764 & & \\
\hline & $(-0.09)$ & $(0.12)$ & & \\
\hline \multirow[t]{2}{*}{ Treat $\times Y_{2011}$} & -0.0153 & -0.00976 & & \\
\hline & $(-0.25)$ & $(-0.16)$ & & \\
\hline
\end{tabular}




\begin{tabular}{|c|c|c|c|c|}
\hline \multirow[t]{2}{*}{ Treat $\times Y_{2012}$} & 0.0401 & \multicolumn{3}{|l|}{0.0396} \\
\hline & $(0.66)$ & $(0.65)$ & & \\
\hline \multirow[t]{2}{*}{ Treat $\times Y_{2013}$} & -0.00549 & -0.00648 & & \\
\hline & $(-0.09)$ & $(-0.11)$ & & \\
\hline \multirow[t]{2}{*}{ Treat $\times Y_{2014}$} & & & $0.159^{* *}$ & $0.127^{* *}$ \\
\hline & & & $(2.46)$ & (1.99) \\
\hline \multirow[t]{2}{*}{ Treat $\times Y_{2015}$} & & & $0.132^{* *}$ & $0.107^{*}$ \\
\hline & & & $(2.04)$ & $(1.67)$ \\
\hline \multirow[t]{2}{*}{ Treat $\times Y_{2016}$} & & & $0.141^{* *}$ & $0.109^{*}$ \\
\hline & & & $(2.18)$ & $(1.69)$ \\
\hline \multirow[t]{2}{*}{ Treat $\times Y_{2017}$} & & & $0.205^{* * *}$ & $0.162^{* *}$ \\
\hline & & & $(3.17)$ & $(2.50)$ \\
\hline \multirow[t]{2}{*}{ _cons } & $1.000^{* * *}$ & $4.414^{* *}$ & $0.801^{* * *}$ & $4.309^{* *}$ \\
\hline & $(20.63)$ & $(2.29)$ & $(17.37)$ & $(2.04)$ \\
\hline Control variables & no & yes & no & yes \\
\hline Province fixed & yes & yes & yes & yes \\
\hline Year fixed & yes & yes & yes & yes \\
\hline $\mathrm{N}$ & 348 & 348 & 348 & 348 \\
\hline$A-R^{2}$ & 0.802 & 0.807 & 0.755 & 0.766 \\
\hline
\end{tabular}
conducted a counterfactual test, which means that we randomly extracted 6 provinces to form new

353 dummy samples, and repeated the DID regression. If the coefficient of Treat $\times Y$ is significant, our 354 conclusions is questionable; otherwise, our results are robust. Through three random sampling, three 355 groups of provinces are selected and the test results are shown in Table 4. No matter whether the 356 control variables are added or not, the coefficients of Treat $\times Y$ are always not significant, illustrating 357 that dummy emission trading has no effects on CEI in pilot areas. To sum up, Our analysis and 358 conclusions are reliable.

Table 4 Counterfactual test 


\begin{tabular}{|c|c|c|c|c|c|c|}
\hline \multirow[t]{2}{*}{ Variables } & \multicolumn{2}{|l|}{ Group 1} & \multicolumn{2}{|l|}{ Group 2} & \multicolumn{2}{|l|}{ Group 3} \\
\hline & (1) & (2) & (3) & (4) & (5) & (6) \\
\hline \multirow[t]{2}{*}{ Treat $\times Y$} & -0.0508 & -0.0142 & -0.0126 & -0.0219 & -0.0133 & 0.0335 \\
\hline & $(-1.33)$ & $(-0.36)$ & $(-0.33)$ & $(-0.57)$ & $(-0.35)$ & $(0.87)$ \\
\hline \multirow[t]{2}{*}{ lnwage } & & $-0.382^{*}$ & & $-0.371^{*}$ & & $-0.377^{*}$ \\
\hline & & $(-1.95)$ & & $(-1.92)$ & & $(-1.95)$ \\
\hline \multirow[t]{2}{*}{$\operatorname{lnrd}$} & & $0.112^{* *}$ & & $0.109^{* *}$ & & $0.119^{* *}$ \\
\hline & & (2.10) & & $(2.02)$ & & $(2.21)$ \\
\hline \multirow[t]{2}{*}{ lnind } & & $-0.314^{* *}$ & & $-0.329^{* *}$ & & $-0.329^{* *}$ \\
\hline & & $(-2.14)$ & & $(-2.38)$ & & $(-2.38)$ \\
\hline \multirow[t]{2}{*}{ lnene } & & $-0.172^{* * *}$ & & $-0.180^{* * *}$ & & $-0.186^{* * *}$ \\
\hline & & $(-2.98)$ & & $(-3.12)$ & & $(-3.18)$ \\
\hline \multirow[t]{2}{*}{ lnenr } & & 0.0193 & & 0.0202 & & 0.0179 \\
\hline & & $(0.70)$ & & $(0.73)$ & & $(0.65)$ \\
\hline \multirow[t]{2}{*}{ lnopen } & & 0.0184 & & 0.0220 & & 0.0179 \\
\hline & & $(0.52)$ & & $(0.62)$ & & $(0.51)$ \\
\hline \multirow[t]{2}{*}{ _cons } & $0.839^{* * *}$ & $3.845^{*}$ & $0.842^{* * *}$ & $3.791^{*}$ & $0.842^{* * *}$ & $3.714^{*}$ \\
\hline & (18.19) & $(1.79)$ & (18.19) & $(1.78)$ & $(18.19)$ & $(1.74)$ \\
\hline Province fixed & yes & yes & yes & yes & yes & yes \\
\hline Year fixed & yes & yes & yes & yes & yes & yes \\
\hline $\mathrm{N}$ & 348 & 348 & 348 & 348 & 348 & 348 \\
\hline$A-R^{2}$ & 0.743 & 0.760 & 0.742 & 0.760 & 0.742 & 0.761 \\
\hline
\end{tabular}

Notes: The three groups of randomly sampled provinces are: (1) Inner Mongolia, Anhui, Fujian, Sichuan, Qinghai,

361 Ningxia; (2) Shanxi, Jilin, Shandong, Henan, Guangxi, Guizhou; (3) Liaoning, Jiangxi, Hunan, Shaanxi , Gansu, 362 Xinjiang.

5.4 Analysis of regional heterogeneity

Considering the unevenness of China's different regions, we further studied the regional heterogeneity of ultimate policy effects. According to the standards published by the National Bureau of statistics, China is divided into three regions: eastern region, central region and western region. 

5. The coefficients of Treat $\times Y$ in the eastern and western regions are significant, and the absolute value of the western region is greater than that in the eastern region, whereas the central region is not significant, which indicates that the policy effect of emission trading shows regional heterogeneity. The

371 western region is unfavorable in terms of location and economy, but it is rich in natural resources, with

372 a great room for improvement in carbon emission reduction. The eastern region is economically and

373 technologically advanced, leading to small room in carbon abatement. For the central region, it has no

374 obvious advantages in both economy and resources, resulting in poor emission reduction effect.

375 Table 5 Regional heterogeneity

\begin{tabular}{|c|c|c|c|c|c|c|}
\hline \multirow[t]{2}{*}{ Variables } & \multicolumn{2}{|l|}{ Eastern } & \multicolumn{2}{|l|}{ Central } & \multicolumn{2}{|l|}{ Western } \\
\hline & (1) & (2) & (3) & (4) & (5) & (6) \\
\hline \multirow[t]{2}{*}{ Treat $\times Y$} & $0.245^{* * *}$ & $0.132^{*}$ & -0.0633 & -0.0647 & $0.219^{* * *}$ & $0.264^{* * *}$ \\
\hline & $(3.88)$ & $(1.79)$ & $(-1.54)$ & $(-1.50)$ & $(2.85)$ & $(3.04)$ \\
\hline \multirow[t]{2}{*}{ lnwage } & & -0.283 & & -0.300 & & $-0.750^{* * *}$ \\
\hline & & $(-0.59)$ & & $(-1.46)$ & & $(-2.64)$ \\
\hline \multirow[t]{2}{*}{$\operatorname{lnrd}$} & & -0.118 & & 0.0454 & & 0.109 \\
\hline & & $(-0.99)$ & & $(0.81)$ & & $(1.16)$ \\
\hline \multirow[t]{2}{*}{ lnind } & & -0.503 & & $0.265^{* *}$ & & $-0.642^{* *}$ \\
\hline & & $(-1.36)$ & & $(2.35)$ & & $(-2.12)$ \\
\hline \multirow[t]{2}{*}{ lnene } & & $-0.430^{*}$ & & -0.00637 & & $-0.158^{* *}$ \\
\hline & & $(-1.90)$ & & $(-0.07)$ & & $(-2.21)$ \\
\hline \multirow[t]{2}{*}{ lnenr } & & -0.0207 & & -0.00959 & & $0.142^{* * *}$ \\
\hline & & $(-0.38)$ & & $(-0.34)$ & & $(3.12)$ \\
\hline \multirow[t]{2}{*}{ lnopen } & & -0.129 & & -0.0222 & & 0.0317 \\
\hline & & $(-0.79)$ & & $(-0.54)$ & & $(0.73)$ \\
\hline \multirow[t]{2}{*}{ _cons } & $0.694^{* * *}$ & 5.161 & $0.211^{* * *}$ & 1.564 & $0.224^{* * *}$ & $8.748^{* * *}$ \\
\hline & (10.19) & $(1.00)$ & $(7.51)$ & $(0.79)$ & $(4.58)$ & $(2.73)$ \\
\hline Province fixed & yes & yes & yes & yes & yes & yes \\
\hline Year fixed & yes & yes & yes & yes & yes & yes \\
\hline $\mathrm{N}$ & 120 & 120 & 96 & 96 & 132 & 132 \\
\hline
\end{tabular}




\begin{tabular}{lllllll}
\hline $\mathrm{A}^{-\mathrm{R}^{2}}$ & 0.734 & 0.746 & 0.643 & 0.687 & 0.286 & 0.362 \\
\hline
\end{tabular}

Notes: (1) Eastern Region: Beijing, Tianjin, Hebei, Liaoning, Shanghai, Jiangsu, Zhejiang, Fujian, Shandong and Guangdong (2) Central region: Shanxi, Jilin, Heilongjiang, Anhui, Jiangxi, Henan, Hubei, Hunan (3) Western region: Inner Mongolia, Guangxi, Chongqing, Sichuan, Guizhou, Yunnan, Shaanxi, Gansu, Qinghai, Ningxia, Xinjiang.

\subsection{Mediating results analysis}

According to the above analysis, China's emission trading has a sustained and significant effect on the improvement of CEI, so how does this effect work? To answer this question, we further investigated the influencing mechanisms of emission trading based on $\mathrm{H} 2$ to $\mathrm{H} 4$ and model (5)-(7), and the results are shown in Table 6.

First, we examined the mediating effect of lnrd. Column (1) displays the regression results of model (5). The significantly positive coefficient of Treat $\times Y$ indicates that China's emission trading has significantly improved CEI. Then, the results of model (6) are listed in column (2). The coefficient of Treat $\times Y$ is significantly positive, suggesting that emission trading promotes technology innovation in the pilot area. Finally, column (3) shows the results based on model (7). The coefficients of Treat $\times Y$ and $\ln r d$ are both significantly positive, and after introducing $\ln r d$, the absolute value of $\beta_{3}$ is smaller than $\beta_{1}$, which illustrates that the mediating effect of lnrd exists and emission trading can improve CEI by stimulating technology innovation. Thus, $\mathrm{H} 2$ is verified.

Second, we tested the mediating variable lnene. The coefficient of Treat $\times Y$ is the same in column (1). The coefficient of Treat $\times Y$ in column (4) is significantly negative, indicating that emission trading significantly reduces the energy intensity of the pilot areas. In column (5), the coefficient of lnene is significantly negative, and the absolute value of the coefficient of Treat $\times Y$ is lower than that in column (1), which denotes that emission trading can improve CEI by reducing energy intensity. Thus, H3 is verified. The reduction of energy intensity means the reduction of electricity consumption required to increase the unit GDP, which has greatly promoted the reduction of carbon emissions in iron and steel industry.

Third, we checked the mediating effect of lnest. Column (1) remains the same. The coefficient of Treat $\times Y$ in column (6) is significantly negative, implying that the implementation of emission trading has adjusted the energy structure, that is, increased the proportion of clean energy. In column (7), the coefficients of Treat $\times Y$ and lnest are significantly positive, and the absolute value of the coefficient of Treat $\times Y$ is smaller than that of column (1), which means that emission trading can improve CEI by adjusting energy structure, so $\mathrm{H} 4$ is verified.

Table 6 Test results of the mediating effect

\begin{tabular}{llllllll} 
Variables & $(1)$ & $(2)$ & $(3)$ & $(4)$ & $(5)$ & $(6)$ & $(7)$ \\
\cline { 2 - 7 } & CEI & lnrd & CEI & lnene & CEI & lnest & CEI \\
\hline
\end{tabular}




\begin{tabular}{|c|c|c|c|c|c|c|c|}
\hline Treat $\times Y$ & $\begin{array}{l}0.153^{* * *} \\
(4.07)\end{array}$ & $\begin{array}{l}0.0807^{* *} \\
(2.00)\end{array}$ & $\begin{array}{l}0.145^{* * *} \\
(3.85)\end{array}$ & & & & \\
\hline $\ln r d$ & & & $\begin{array}{l}0.101^{*} \\
(1.89)\end{array}$ & & & & \\
\hline Treat $\times Y$ & $\begin{array}{l}0.153^{* * *} \\
(4.07)\end{array}$ & & & $\begin{array}{l}-0.144^{* * *} \\
(-3.88)\end{array}$ & $\begin{array}{l}0.133^{* * *} \\
(3.48)\end{array}$ & & \\
\hline lnene & & & & & $\begin{array}{l}-0.140^{* *} \\
(-2.43)\end{array}$ & & \\
\hline Treat $\times Y$ & $\begin{array}{l}0.153^{* * *} \\
(4.07)\end{array}$ & & & & & $\begin{array}{l}0.102^{* * *} \\
(3.33)\end{array}$ & $\begin{array}{l}0.138^{* * *} \\
(3.62)\end{array}$ \\
\hline lnest & & & & & & & $\begin{array}{l}0.151^{* *} \\
(2.15)\end{array}$ \\
\hline lnwage & $\begin{array}{l}-0.508^{* * *} \\
(-2.68)\end{array}$ & $\begin{array}{l}-0.537^{* * *} \\
(-2.64)\end{array}$ & $\begin{array}{l}-0.454^{* *} \\
(-2.38)\end{array}$ & $\begin{array}{l}0.364^{*} \\
(1.94)\end{array}$ & $\begin{array}{l}-0.457^{* *} \\
(-2.42)\end{array}$ & $\begin{array}{l}0.0556 \\
(0.36)\end{array}$ & $\begin{array}{l}-0.516^{* * *} \\
(-2.74)\end{array}$ \\
\hline lnind & $\begin{array}{l}-0.193 \\
(-1.49)\end{array}$ & $\begin{array}{l}0.904^{* * *} \\
(6.47)\end{array}$ & $\begin{array}{l}-0.284^{* *} \\
(-2.06)\end{array}$ & $\begin{array}{l}0.00996 \\
(0.08)\end{array}$ & $\begin{array}{l}-0.192 \\
(-1.49)\end{array}$ & $\begin{array}{l}-0.000856 \\
(-0.01)\end{array}$ & $\begin{array}{l}-0.193 \\
(-1.49)\end{array}$ \\
\hline lnenr & $\begin{array}{l}0.0146 \\
(0.54)\end{array}$ & $\begin{array}{l}-0.00959 \\
(-0.33)\end{array}$ & $\begin{array}{l}0.0156 \\
(0.58)\end{array}$ & $\begin{array}{l}0.107^{* * *} \\
(4.03)\end{array}$ & $\begin{array}{l}0.0296 \\
(1.08)\end{array}$ & $\begin{array}{l}-0.0419^{*} \\
(-1.91)\end{array}$ & $\begin{array}{l}0.0209 \\
(0.78)\end{array}$ \\
\hline lnopen & $\begin{array}{l}0.0351 \\
(1.02)\end{array}$ & $\begin{array}{l}-0.0409 \\
(-1.11)\end{array}$ & $\begin{array}{l}0.0392 \\
(1.15)\end{array}$ & $\begin{array}{l}-0.108^{* * *} \\
(-3.19)\end{array}$ & $\begin{array}{l}0.0200 \\
(0.58)\end{array}$ & $\begin{array}{l}-0.0151 \\
(-0.54)\end{array}$ & $\begin{array}{l}0.0374 \\
(1.10)\end{array}$ \\
\hline _cons & $\begin{array}{l}6.724^{* * *} \\
(3.48)\end{array}$ & $\begin{array}{l}14.66^{* * *} \\
(7.04)\end{array}$ & $\begin{array}{l}5.251^{* *} \\
(2.53)\end{array}$ & $\begin{array}{l}-7.560^{* * *} \\
(-3.95)\end{array}$ & $\begin{array}{l}5.667^{* * *} \\
(2.88)\end{array}$ & $\begin{array}{l}2.683^{*} \\
(1.70)\end{array}$ & $\begin{array}{l}6.320^{* * *} \\
(3.27)\end{array}$ \\
\hline Province fixed & yes & yes & yes & yes & yes & yes & yes \\
\hline Year fixed & yes & yes & yes & yes & yes & yes & yes \\
\hline $\mathrm{N}$ & 348 & 348 & 348 & 348 & 348 & 348 & 348 \\
\hline$A-R^{2}$ & 0.763 & 0.984 & 0.765 & 0.967 & 0.767 & 0.984 & 0.766 \\
\hline
\end{tabular}


With the development of carbon trading market in China, it is necessary to conduct accurate empirical evaluation on the effect of emission trading. By applying the panel data of China's 29 provinces and cities from 2006 to 2017, this paper employs a DEA-SBM model to measure carbon emission efficiency of iron and steel industry (CEI), and then adopts a DID method to evaluate the impact of emission trading on CEI. Simultaneously, the counterfactual test is utilized to examine the robustness of our results. In addition, we discuss the regional heterogeneity of emission trading in China's three regions. Finally, we explore the influencing channels in terms of technology innovation, energy intensity and energy structure. The main conclusions are as follows.

China's emission trading has achieved satisfactory results in carbon emission reduction of iron and steel industry, increasing the average annual CEI by $12.6 \%$ in pilot regions. Although there was a slight decline in the second year of policy implementation, overall, the policy effect increased with the passage of time. However, the effects of emission trading show obvious heterogeneity across diverse regions, with the significant effects in the western region and the second in eastern region, but not significant in the central region. From the mediating results, emission trading can increase CEI by stimulating technology innovation, reducing energy intensity and adjusting energy structure. Moreover, economic development level and industrial structure have hindered the improvement of CEI, while environmental regulation and opening degree have no significant correlation with CEI.

6.2 Policy implications

Based on the above conclusions, some specific policy implications are proposed as follows.

First, it is recommended that the government establish a reasonable distribution system and expand the coverage of emission trading to maximize its potential in carbon reduction of iron and steel industry. According to the characteristics of iron and steel industry, accelerating the establishment of "baseline method" quota allocation method based on major carbon emission processes such as coking, sintering and ironmaking. Moreover, formulating the development of a carbon footprint accounting method covering the whole process of iron and steel production to facilitate the assessment and management of carbon quotas at the enterprise level.

Second, it is recommended that the government fully consider the regional heterogeneity in the implementation of emission trading and develop differentiated emission reduction strategies. To narrow the difference of policy effect of iron and steel industry in different regions, the fairness of policy design should be emphasized in the process of constructing carbon trading market according to the economic potential and natural endowment of each region.

Third, it is recommended that iron and steel enterprises develop energy-conversation and emissions-reduction technologies such as hydrogen metallurgy technology and carbon capture and storage technology (CCS). Moreover, in order to optimize the energy structure and reduce energy intensity, enterprises should actively develop and utilize clean energy such as natural gas. In articular, 
the awareness of energy conservation of enterprises should be enhanced to raise energy utilization efficiency and achieve green production as soon as possible.

Finally, it is recommended that the government strengthen international exchanges and learn from other countries' experience in policy implementation and low-carbon development. Besides, the government should establish a reasonable environmental regulation system to maximize enterprises profits while protecting the environment. Additionally, industrial structure should be optimized to reduce carbon emissions of iron and steel industry. On the one hand, the traditional manufacturing industry should be transformed and upgraded to change an unfavorable position in the carbon market; on the other hand, the development of tertiary industry should be promoted as the main driver of economic development.

Authors contributions Calculation and analysis: Xiping Wang; writing: Sujing Wang

Competing interests Not applicable

Funding Hebei Provincial Social Science Foundation Project (Project Number: HB19YJ011)

Ethical approval Not applicable

Consent to participate Not applicable

Consent to publish Not applicable

Availability of data and materials The datasets used during the current study are available from the corresponding author on reasonable request.

\section{Appendix A.}

Table 7 Provincial average CEI from 2006 to 2017

\begin{tabular}{lcccccccccccccccc}
\hline Province & 2006 & 2007 & 2008 & 2009 & 2010 & 2011 & 2012 & 2013 & 2014 & 2015 & 2016 & 2017 & Average \\
\hline Beijing & 0.64 & 0.19 & 1.00 & 1.00 & 1.00 & 1.00 & 1.00 & 1.00 & 1.00 & 1.00 & 1.00 & 1.00 & 0.90 \\
Tianjin & 0.38 & 0.33 & 0.39 & 0.64 & 0.60 & 1.00 & 1.00 & 1.00 & 1.00 & 1.00 & 1.00 & 1.00 & 0.78 \\
Hebei & 0.31 & 0.26 & 0.23 & 0.30 & 0.41 & 0.57 & 0.44 & 0.47 & 0.47 & 0.44 & 0.41 & 0.32 & 0.39 \\
Shanxi & 0.17 & 0.17 & 0.16 & 0.23 & 0.25 & 0.38 & 0.28 & 0.40 & 0.43 & 0.33 & 0.36 & 0.23 & 0.28 \\
Inner Mongolia & 0.13 & 0.13 & 0.18 & 0.26 & 0.18 & 0.23 & 0.17 & 0.19 & 0.17 & 0.19 & 0.20 & 0.14 & 0.18 \\
Liaoning & 0.15 & 0.12 & 0.10 & 0.19 & 0.21 & 0.29 & 0.28 & 0.30 & 0.27 & 0.23 & 0.15 & 0.18 & 0.21 \\
Jilin & 0.14 & 0.13 & 0.13 & 0.21 & 0.15 & 0.26 & 0.30 & 0.51 & 0.37 & 0.32 & 0.29 & 0.14 & 0.25 \\
Heilongjiang & 0.13 & 0.13 & 0.13 & 0.19 & 0.14 & 0.17 & 0.12 & 0.15 & 0.16 & 0.11 & 0.10 & 0.05 & 0.13 \\
Shanghai & 0.32 & 0.22 & 0.19 & 0.29 & 1.00 & 1.00 & 1.00 & 0.80 & 1.00 & 1.00 & 1.00 & 1.00 & 0.73 \\
Jiangsu & 1.00 & 1.00 & 1.00 & 1.00 & 1.00 & 1.00 & 1.00 & 1.00 & 1.00 & 1.00 & 1.00 & 1.00 & 1.00 \\
\hline
\end{tabular}




\begin{tabular}{|c|c|c|c|c|c|c|c|c|c|c|c|c|c|}
\hline Zhejiang & 0.51 & 0.51 & 0.50 & 1.00 & 1.00 & 0.70 & 0.65 & 1.00 & 0.73 & 0.67 & 0.69 & 0.44 & 0.70 \\
\hline Anhui & 0.12 & 0.11 & 0.17 & 0.27 & 0.25 & 0.44 & 0.27 & 0.36 & 0.43 & 0.38 & 0.41 & 0.25 & 0.29 \\
\hline Fujian & 0.36 & 0.37 & 0.34 & 0.23 & 0.33 & 0.42 & 0.27 & 0.36 & 0.43 & 0.41 & 0.51 & 0.39 & 0.37 \\
\hline Jiangxi & 0.35 & 0.13 & 0.09 & 0.29 & 0.20 & 0.23 & 0.25 & 0.28 & 0.29 & 0.29 & 0.25 & 0.15 & 0.23 \\
\hline Shandong & 0.38 & 0.61 & 0.64 & 0.44 & 0.38 & 0.51 & 0.48 & 0.35 & 0.33 & 0.23 & 0.24 & 0.19 & 0.40 \\
\hline Henan & 0.19 & 0.19 & 0.21 & 0.20 & 0.24 & 0.32 & 0.30 & 0.39 & 0.41 & 0.42 & 0.49 & 0.36 & 0.31 \\
\hline Hubei & 0.16 & 0.14 & 0.17 & 0.23 & 0.41 & 0.35 & 0.46 & 0.45 & 0.35 & 0.29 & 0.32 & 0.23 & 0.30 \\
\hline Hunan & 0.19 & 0.16 & 0.17 & 0.14 & 0.19 & 0.29 & 0.24 & 0.34 & 0.31 & 0.29 & 0.33 & 0.26 & 0.24 \\
\hline Guangdong & 0.40 & 0.49 & 0.42 & 0.43 & 0.77 & 0.68 & 0.61 & 0.86 & 0.53 & 0.49 & 0.64 & 0.60 & 0.58 \\
\hline Guangxi & 0.22 & 0.21 & 0.17 & 0.19 & 0.25 & 0.36 & 0.26 & 0.41 & 0.49 & 0.49 & 0.55 & 0.35 & 0.33 \\
\hline Chongqing & 0.08 & 0.08 & 0.09 & 0.09 & 0.17 & 0.18 & 0.24 & 0.35 & 0.59 & 0.44 & 0.34 & 0.27 & 0.24 \\
\hline Sichuan & 1.00 & 1.00 & 0.60 & 0.19 & 0.19 & 0.20 & 0.28 & 0.25 & 0.31 & 0.37 & 0.40 & 0.31 & 0.42 \\
\hline Guizhou & 0.22 & 0.21 & 0.20 & 0.21 & 0.13 & 0.15 & 0.13 & 0.22 & 0.22 & 0.24 & 0.23 & 0.10 & 0.19 \\
\hline Yunnan & 0.16 & 0.20 & 0.19 & 0.27 & 0.17 & 0.21 & 0.23 & 0.26 & 0.27 & 0.21 & 0.21 & 0.19 & 0.21 \\
\hline Shaanxi & 0.24 & 0.23 & 0.19 & 0.32 & 0.19 & 0.23 & 0.25 & 0.35 & 0.29 & 0.39 & 0.44 & 0.22 & 0.28 \\
\hline Gansu & 0.14 & 0.15 & 0.14 & 0.31 & 0.22 & 0.22 & 0.25 & 0.39 & 0.53 & 0.45 & 0.18 & 0.15 & 0.26 \\
\hline Qinghai & 0.23 & 0.12 & 0.21 & 0.21 & 0.17 & 0.17 & 0.14 & 0.19 & 0.19 & 0.23 & 0.22 & 0.15 & 0.19 \\
\hline Ningxia & 0.59 & 0.36 & 0.29 & 0.16 & 0.14 & 0.25 & 0.19 & 0.18 & 0.21 & 0.30 & 0.35 & 0.24 & 0.27 \\
\hline Xinjiang & 0.15 & 0.14 & 0.15 & 0.24 & 0.22 & 0.19 & 0.12 & 0.16 & 0.16 & 0.15 & 0.21 & 0.18 & 0.17 \\
\hline Eastern & 0.45 & 0.41 & 0.48 & 0.55 & 0.67 & 0.72 & 0.67 & 0.71 & 0.68 & 0.65 & 0.66 & 0.61 & 0.61 \\
\hline Central & 0.18 & 0.15 & 0.15 & 0.22 & 0.23 & 0.30 & 0.28 & 0.36 & 0.34 & 0.31 & 0.32 & 0.21 & 0.25 \\
\hline Western & 0.29 & 0.26 & 0.22 & 0.22 & 0.18 & 0.22 & 0.21 & 0.27 & 0.31 & 0.31 & 0.30 & 0.21 & 0.25 \\
\hline National & 0.31 & 0.28 & 0.29 & 0.34 & 0.36 & 0.41 & 0.39 & 0.45 & 0.45 & 0.43 & 0.43 & 0.35 & 0.37 \\
\hline
\end{tabular}

\section{References}

466 Alberola E, Chevallier J, Chèze B (2008) Emissions Compliances and Carbon Prices under the EU ETS: A Country Specific Analysis of Industrial Sectors. Journal of Policy Modeling 31(3)

468 Anger A (2009) Including aviation in the European emissions trading scheme: Impacts on the industry, $\mathrm{CO}_{2}$ 
Chen S, Shi A, Wang X (2020) Carbon emission curbing effects and influencing mechanisms of China's Emission Trading Scheme: The mediating roles of technique effect, composition effect and allocation effect. Journal of Cleaner Production 264:121700

Chen Y (2008) Climate Policies and the Power Sector: Challenges and Issues. Journal of Energy Engineering 134(2):31-32

Cheng B, Dai H, Wang P, Zhao D, Masui T (2015) Impacts of carbon trading scheme on air pollutant emissions in Guangdong Province of China. Energy for Sustainable Development 27:174-185

Cheng F L, Lin S J, Lewis C (2008) Analysis of the impacts of combining carbon taxation and emission trading on

China's National Bureau of Statistics (CNBSa) (2006-2017) China Statistic Yearbook. China Statistical Press, Beijing

China's National Bureau of Statistics (CNBSb) (2006-2017) China Energy Statistic Yearbook. China Statistical Press, Beijing

China's National Bureau of Statistics (CNBSc) (2006-2017) China Iron and Steel Industry Statistical Yearbook

Hidalgo I, Szabo L, Ciscar J C, Soria A (2004) Technological prospects and $\mathrm{CO}_{2}$ emission trading analyses in the 
Hübler M, Voigt S, Löschel A (2014) Designing an emissions trading scheme for China-An up-to-date climate policy assessment. Energy Policy 75:57-72

IPCC (Intergovernmental Panel on Climate Change) (2006), IPCC Guidelines for National Greenhouse Gas Inventories, IPCC, Bracknell

Kara M, Syri S, Lehtil A, Helynen S, Kekkonen V, Ruska M, Forsström J (2008) The impacts of EU CO2 emissions trading on electricity markets and electricity consumers in Finland. Energy Economics 30(2):193-211

Li W, Jia Z (2016) The impact of emission trading scheme and the ratio of free quota: A dynamic recursive CGE model in China. Applied Energy 174:1-14

Lund P (2007) Impacts of EU carbon emission trade directive on energy-intensive industries — Indicative micro-economic analyses. Ecological Economics 63(4):799-806

Nong D, Trung H, Nguyen, Wang C, Khuc Q V (2020) The environmental and economic impact of the emissions trading scheme (ETS) in Vietnam. Energy Policy 140:111362

Shen J, Tang P, Zeng H (2020) Does China's carbon emission trading reduce carbon emissions? Evidence from listed firms. Energy for Sustainable Development 59:120-129

Shen L, Song X, Wu Y, Liao S, Zhang X (2016) Interpretive Structural Modeling based factor analysis on the implementation of Emission Trading System in the Chinese building sector. Journal of Cleaner Production $127: 214-227$

Springer C, Evans S, Lin J, David R H (2019) Low carbon growth in China: The role of emissions trading in a transitioning economy. Applied Energy 235:1118-1125

Tang K, Liu Y, Zhou D, Yuan Q (2020) Urban carbon emission intensity under emission trading system in a developing economy: evidence from 273 Chinese cities. Environmental Science and Pollution Research 28(5)

Tao Z (2017) A Stochastic Bilevel Programming Model for the Iron and Steel Production Optimization Problem Under Carbon Trading Mechanism. Springer Singapore

Tone K (2003) Dealing with undesirable outputs in DEA: A slacks-based measure (SBM) approach. GRIPS Research Report Series

Tran T M, Siriwardana M, Meng S, Nong D (2019) Impact of an emissions trading scheme on Australian households: A computable general equilibrium analysis. Journal of Cleaner Production 221:439-459

Wang Y M, Pan S M (2009) Status and trends of China carbon trading market under financial crisis. Economic Theory and Business Management 11:57-63

Wang H, Chen Z, Wu X, Nie X (2019) Can a carbon trading system promote the transformation of a low-carbon economy under the framework of the porter hypothesis?-Empirical analysis based on the PSM-DID method. Energy Policy 129:930-938 
Wang P, Dai H, Ren S, Zhao D, Masui T (2015) Achieving Copenhagen target through carbon emission trading: Economic impacts assessment in Guangdong Province of China. Energy 79:212-227

Wen Y, Hu P, Li J, Liu Q, Shi L, Ewing J, Ma Z (2020) Does China's carbon emissions trading scheme really work? A case study of the hubei pilot. Journal of Cleaner Production 277

Xian Y, Wang K, Wei Y M, Huang Z (2019) Would China's power industry benefit from nationwide carbon emission permit trading? An optimization model-based ex post analysis on abatement cost savings. Applied Energy 235:973-986

Yang L, Li F, Zhang X (2016) Chinese companies' awareness and perceptions of the emissions trading scheme (ETS): evidence from a national survey in China. Energy Policy 98:254-265

Zhang H, Duan M, Zhang P (2019b) Analysis of the Impact of China's Emissions Trading Scheme on Reducing Carbon Emissions. Energy Procedia 158:3596-3601

Zhang L, Li Y, Jia Z (2018) Impact of carbon allowance allocation on power industry in China's carbon trading market: Computable general equilibrium based analysis. Applied Energy 229:814-827

Zhang W, Zhang N, Yu Y (2019c) Carbon mitigation effects and potential cost savings from carbon emissions trading in China's regional industry. Technological Forecasting and Social Change 141:1-11

Zhang Y, Peng Y, Ma C (2017) Can environmental innovation facilitate carbon emissions reduction? Evidence from China. Energy Policy 100:18-28

Zhang Y, Zhang J (2019a) Estimating the impacts of emissions trading scheme on low-carbon development. Journal of Cleaner Production 238:117913

Zhou B, Zhang C, Song H, Wang Q W (2019) How does emission trading reduce China's carbon intensity? An exploration using a decomposition and difference-in-differences approach. Science of the Total Environment $676: 514-523$ 